\title{
Population-Based Estimation of the Preterm Birth Rate in Lilongwe, Malawi: Making Every Birth Count
}

\author{
Kathleen M. Antony, MD, MSCI ${ }^{1,2,30}$ Peter N. Kazembe, MBChB ${ }^{4}$ Ryan M. Pace, $\mathrm{PhD}^{1,5}$ \\ Judy Levison, MD, MPH ${ }^{1}$ Henry Phiri, MD ${ }^{6}$ Grace Chiudzu, MD ${ }^{6}$ Ronald Alan Harris, $\mathrm{PhD}^{1}$ \\ Rose Chirwa ${ }^{4}$ Mary Nyondo ${ }^{4}$ Ellina Marko ${ }^{4}$ Andrew Chigayo ${ }^{4}$ Debora Nanthuru ${ }^{4}$ Bertha Banda ${ }^{4}$ \\ Nicholas Twyman, BS ${ }^{1}$ Susan M. Ramin, MD ${ }^{1,2}$ Susan P. Raine, MD ${ }^{1}$ Michael A. Belfort, MD, PhD ${ }^{1,2}$ \\ Kjersti M. Aagaard, MD, PhD ${ }^{1,2}$
}

${ }^{1}$ Department of Obstetrics and Gynecology, Baylor College of Medicine, Houston, Texas

${ }^{2}$ Division of Maternal-Fetal Medicine, Department of Obstetrics and Gynecology, Baylor College of Medicine, Houston, Texas

${ }^{3}$ Division of Maternal-Fetal Medicine, Department of Obstetrics and Gynecology, University of Wisconsin-Madison, Madison, Wisconsin

${ }^{4}$ Department of Pediatrics, Baylor College of Medicine Children's Clinical Center of Excellence, Kamuzu Central Hospital, Lilongwe, Malawi

${ }^{5}$ Department of Immunology, University of Idaho, Moscow, Idaho

${ }^{6}$ Department of Obstetrics and Gynecology, Kamuzu Central

Hospital, Lilongwe, Malawi

Am J Perinatol Rep 2020;10:e78-e86.
Address for correspondence Kathleen M. Antony, MD, MSCl, Division of Maternal-Fetal Medicine, Department of Obstetrics and Gynecology, University of Wisconsin-Madison, 202 South Park Street, Madison, WI 53715-1599 (e-mail: kantony@wisc.edu).

\begin{abstract}
Keywords

- preterm birth

- Malawi

- global health

- global

- maternal health

Objective The objective of this study was to perform a population-based estimation of the preterm birth (PTB) rate in regions surrounding Lilongwe, Malawi.

Study Design We partnered with obstetrician specialists, community health workers, local midwives, and clinicians in a $50 \mathrm{~km}$ region surrounding Lilongwe, Malawi, to perform a population-based estimation of the PTB rate during the study period from December 1, 2012 to May 19, 2015.

Results Of the 14,792 births captured, $19.3 \%$ of births were preterm, including preterm early neonatal deaths. Additional PTB risk factors were similarly prevalent including domestic violence, HIV, malaria, anemia, and malnutrition.

Conclusion When performing a population-based estimation of the rate of PTB, including women without antenatal care and women delivering at home, the 19.3\% rate of PTB is among the highest recorded globally. This is accompanied by a high rate of risk factors and comorbid conditions.
\end{abstract}

Globally, preterm birth (PTB) accounts for $15.4 \%$ of the 6.3 million children who died in their first 5 years of life in 2013, making it the leading cause of childhood mortality. ${ }^{1,2}$ Malawi has the highest rate of PTB in the world. Estimates of the PTB rate ranging from 7.9 to $29.7 \%{ }^{2-8}$ However, these numbers result from studies with notable potential for bias.
National registries do not always specify the method of gestational age (GA) assessment or the lower GA cut-off to define $\mathrm{PTB},{ }^{3}$ thus they may underestimate PTB by neglecting to include early PTBs ( $<28$ weeks). On the other hand, prospective trials ${ }^{4-6,9}$ require patients to enroll during antenatal care and self-select for patients who are able to seek received

October 9, 2019

accepted

January 24, 2020
DOI https://doi.org/

10.1055/s-0040-1708491. ISSN 2157-6998.
Copyright $\odot 2020$ by Thieme Medical

Publishers, Inc., 333 Seventh Avenue, New York, NY 10001, USA. Tel: +1(212) 760-0888.
License terms

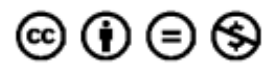


and obtain regular prenatal care. Studies utilizing active surveillance of rural and urban villages, and both local health centers and regional referral centers, overcome both these limitations and aim to capture all comers using the best available data; however, relatively rigorous assessment of GA may be lacking. ${ }^{10}$

While the etiology of PTB is multifactorial, its association with infection and inflammation is well established. ${ }^{11-22}$ Therefore, we also queried comorbidities associated with or causal to PTB, including domestic violence, HIV, malaria, anemia, and malnutrition.

Based on prior estimates, we hypothesized that the rate of PTB would be approximately $20 \%$. This study sought to (1) perform a population-based estimation of the PTB rate in a 50-km region surrounding Lilongwe, Malawi, using active surveillance of rural and urban villages and both local health centers and regional referral centers to capture all comers using the best available data for assessment of GA, and (2) measure related medical and environmental factors associated with PTB.

\section{Patients and Methods}

This study was approved by the National Health Sciences Research Committee with the Malawi Ministry of Health (institutional review board (IRB)-00003905, Federal Wide Assurance 00005976). Baylor College of Medicine/Texas Children's Hospital in Houston, Texas has an established pediatric HIV clinic in Lilongwe, Malawi, located at Kamuzu Central Hospital $(\mathrm{KCH})$ which is part of the Baylor International Pediatrics AIDS Initiative (BIPAI, Baylor-Malawi). Since 2011, Baylor College of Medicine's Department of Obstetrics and Gynecology has collaborated with the Malawi Ministry of Health and the College of Medicine of Malawi with the goal of expanding obstetrical care and antenatal services with a focus on determining the prevalence of PTB and improving care surrounding preterm labor and PTB.

To perform a population-based estimation of the PTB rate, we partnered with obstetrician specialists, community health workers, local midwives, and clinicians in a $50-\mathrm{km}$ region surrounding Lilongwe, Malawi (the distance from the farthest site, Kabudula, to Lilongwe is $47.5 \mathrm{~km}$ by road). Health centers at the sites of Kabudula and Area 25 (Rural Health Centers) and the sites of Kawale and Area 18 (Urban Health Centers) along with $\mathrm{KCH}$ regional referral hospital were designated as study sites. Local community health workers were assigned to each site plus one program manager (five total) and were tasked with ascertaining data on the population-based rate of PTB. Community health workers are individuals without formal health training whose role is to educate patients and community members through prepared speeches and songs; they also serve as liaisons with the community leaders to further promote health messages.

Data were collected between December 1, 2012 and May 19, 2015 via review of the delivery records and medical records at the participating sites to determine the rate of PTB at each site. We also interviewed women delivering at these centers to ascertain data that would not otherwise be captured in the delivery and medical records with a goal of documenting as many women within the first 24 hours postpartum as feasible. Women of all GAs were included. In these areas, we also conducted standardized home visits by certified and specifically trained community health field workers to ascertain information on women who may have delivered either at home or while in transit to the hospital. The rationale for using both health care facilities and rural village visits was to collect a representative populationbased estimate of PTB and specifically to obtain data on previously overlooked home and rural village births. For participants interviewed at home, interview questions were determined a priori and approved by the Ministry of Health IRB, and included the reason for delivery outside of a health center, the methods used to confirm GA during prenatal care, infant weight, and status as living or demised. For cases of demise, we specifically queried whether the stillbirth was "fresh," which is a local term indicating early neonatal death; we also queried whether the stillbirth was macerated, and the estimated GA. For participants interviewed at their homes, data on comorbidities were ascertained by interview. Data regarding sensitive topics, such as domestic violence and HIV status, were queried privately. Diagnoses, such as preeclampsia, were established by blood pressure assessment with manual sphygmomanometers and blood and urine samples, for those delivering at the hospital. The capacity to make such diagnoses for home births were limited to the resources available to those attending home births; since these deliveries are not supported by the government, home birth practices vary widely. For participants interviewed at health centers or the hospital, the collected information was the same but delivery details and reported comorbidities were confirmed via the use of medical records. As included, the abstracted data were the source of the "best obstetrical" estimated GA as recorded in the birth logs (e.g., fundal height measurements in concordance with ultrasound estimate, if an ultrasound had been performed). The estimate for most study sites is based on last menstrual period in combination with fundal height measurements, but at Kabudula (a rural health center) and $\mathrm{KCH}$ (the referral hospital), complete obstetrical ultrasounds were available to confirm or alter the estimated GA. During the study time period, women receiving antenatal care at these two sites routinely underwent obstetrical ultrasounds at approximately 28 weeks for the dual purpose of confirming GA and to assess fetal position. Accordingly, GA was only adjusted if the ultrasound dates differed from the clinical dates by 21 days or more. ${ }^{23}$

Data were entered in real time directly into a deidentified centralized web-based survey tool which allows for local data entry in Malawi and distant data export and analysis in the United States. (SurveyMonkey Inc., Palo Alto, CA; www.surveymonkey.com) At home visits, participants were specifically asked about home births or deliveries outside of the health centers; if deliveries discussed at home visits occurred at a health center, data were corroborated with the medical records, but a separate entry was not created (to minimize collinearity). 
As this was a population-based assessment to estimate the rate of PTB in a 50-km region surrounding Lilongwe, Malawi, and the surrounding area, no sample size calculation was performed. Demographic data and descriptive statistics are reported. Chi-square, Fisher's exact test, and the Student's $t$-test were performed where appropriate. The estimated GA at delivery by clinical estimates was correlated with ultrasound findings (when available) via Pearson's correlation. All statistical analyses were performed using Prism 6.0 (GraphPad Software Inc., La Jolla, CA) and R version 3.3.1 ( $\mathrm{R}$ Foundation for Statistical Computing, Vienna, Austria).

\section{Results}

During the study period from December 1, 2012 to May 19, 2015 , there were 14,792 births reported. Of these, 14,676 occurred in health centers or hospitals, and 116 occurred in the home or in transit. This is consistent with the goals of the Malawi Ministry of Health, namely, the women deliver at a Health Center or hospital.

Demographic data are shown in - Table 1. The average age of the population was 25.4 (standard deviation $[S D]=5.9$ ) and there was a statistically significant difference in the rate of PTB by maternal age with higher rates among women $<20$ years old and between 30 and 39 years old and also higher rates of PTB among nulliparous women. Women experiencing PTB had a slightly higher body mass index. Less than $1 \%$ of women reported smoking during pregnancy. While very few women reported domestic violence during their pregnancy, those who did experience domestic violence had higher rates of PTB with a relative risk of 1.9 (95\% confidence interval [CI]: 1.2-2.9). Other comorbidities associated with PTB included HIV positive status, malaria, anemia, malnutrition, and hypertensive disorders of pregnancy. These diagnoses were abstracted from the clinical chart for women delivering at the hospital and via interview for women who delivered at home. Women experiencing PTB were also less likely to have undergone an ultrasound during pregnancy with a relative risk of 1.17 (95\% CI: 1.12-1.20). Demographic data and comorbidities by study site are shown in - Table 2.

The total PTB rate was $19.3 \%$ including preterm deliveries with early neonatal deaths. The rate of PTB differed based upon delivery site (health centers or hospital compared with home births). - Table 3 shows birth statistics for the rural health centers and urban health centers together with statistics for the referral hospital $(\mathrm{KCH})$ overall and also for participants referred to the hospital from the rural and urban health centers. While the overall PTB rate in rural populations was primarily driven by PTB deliveries occurring at 34 to 37 weeks of gestation (33.5\% of rural PTB), very PTB births ( $\leq 32$ weeks of gestation) were often transported to the central referral hospital; $82.9 \%$ of deliveries prior to 32 weeks of gestation from rural and urban health centers were referred to $\mathrm{KCH}$. Additionally, this population represented a significant number of the deliveries at $\mathrm{KCH}: 26.6 \%$ of the total deliveries at $\mathrm{KCH}$ that occurred prior to 32 weeks of gestation were referred from rural or urban health centers.
The overall rate of PTB at $\mathrm{KCH}$ was $82.3 \%$; $73.6 \%$ of these were the result of referrals.

There was not a significant difference between the two populations (rural vs. urban health centers) in the PTB rate prior to 37 weeks of gestation (7.1 and 7.0 at the rural and urban health centers, respectively). At the rural hospitals, indicated PTB was rare ( 0 and $0.03 \%$ for the rural and urban health centers, respectively). At $\mathrm{KCH}$, indicated PTB accounted for $7.6 \%$ of PTB. Cesarean birth occurred in $26.7 \%$ of PTB at $\mathrm{KCH}$. We also collected data on early neonatal deaths that account for up to $5.2 \%$ of PTB at $\mathrm{KCH}$.

The percent of births as a function of reported GA and also as a function of birth weight are shown in - Fig. 1. The rural and urban health centers both peaked at 36 weeks GA, respectively, with corresponding birth weights of 2.6 to $3.0 \mathrm{~kg}$. $\mathrm{KCH}$, however, peaked at 38 weeks GA, but with a lower birth weight of 2.1 to $2.5 \mathrm{~kg}$.

To assess the accuracy of the clinically assessed GA, the ultrasound-calculated GA was compared with the estimated delivery date based upon last menstrual period or clinical assessment $(n=170)$. There was significant correlation between the GA based on the two methods. For the reported GA compared with the calculated GA of term deliveries, $R^{2}=0.0637$ with $p<0.001\left(p=6.56 \times 10^{-23}\right)$. For preterm deliveries, the Pearson's correlation between the GA at delivery by clinical estimates and ultrasound assessment was $R^{2}=0.448$ with $p<0.001\left(p=4.6 \times 10^{-24}\right)$.

\section{Discussion}

When performing a population-based estimation of the rate of PTB in this 50-km region surrounding Lilongwe, Malawi, including women without antenatal care and women delivering at home, the rate of PTB was found to be $19.3 \%$. PTB was noted to be associated with maternal age $(<20$ and $30-39$ weeks), slightly higher body mass index, nulliparity, domestic violence, HIV-positive status, malaria, anemia, malnutrition, and no prior obstetric ultrasound. While it may seem paradoxical that $\mathrm{KCH}$ had the most term deliveries but the lowest birth weights, $\mathrm{KCH}$ was also the Ministry of Health designated referral hospital, so had higher rates of deliveries with maternal comorbidities, which may result in lower birth weights.

The $19.3 \%$ rate of PTB is similar to what has previously been reported, including in sonogram-dated populations in Malawi, ${ }^{3-6,9}$ and demonstrates that nearly one out of every five births in Malawi occur preterm. Additionally, prior studies included only women with antenatal care or used national databanks, both of which do not capture women delivering outside of the health care system and which also commonly exclude early preterm deliveries or preterm deliveries with early neonatal demise. ${ }^{3-6,9}$ By utilizing certified and trained community health field workers who went into the rural villages, we were able to capture deliveries in a culturally and socially acceptable manner that would have otherwise been missed. All community health workers and study personnel were Malawian and resided in the communities where they worked, and thus language dialect 
Estimated Preterm Birth Rate in Lilongwe Antony et al. e81

Table 1 Demographic characteristics of women delivering in Lilongwe from December 1, 2012 to May 19,2015

\begin{tabular}{|c|c|c|c|c|c|}
\hline Characteristic & $\%$ or mean & Term & Preterm & p-Value & Relative risk (range) \\
\hline Total & $100.0(n=14,792)$ & $(n=11,931)$ & $(n=2,861)$ & & \\
\hline \multicolumn{6}{|l|}{ Maternal age groups } \\
\hline $\begin{array}{l}\text { Maternal age } \\
\text { mean (SD) }\end{array}$ & $25.4(5.9)$ & $25.4(5.8)$ & $25.4(6.1)$ & 0.7505 & \\
\hline$<20, n(\%)^{\mathrm{a}}$ & $2,261(14.4)$ & $1,748(14.8)$ & $513(18.1)$ & $<0.0001$ & $1.21(1.11-1.32)^{\mathrm{b}}$ \\
\hline $20-29, n(\%)$ & $8,712(59.5)$ & $7,158(60.6)$ & $1,554(54.9)$ & $<0.0001$ & $0.83(0.78-0.89)$ \\
\hline $30-39, n(\%)$ & $3,409(23.3)$ & $2,678(22.7)$ & $731(25.8)$ & 0.0004 & $1.15(1.06-1.24)$ \\
\hline $40-46, n(\%)$ & $255(1.7)$ & 224 (1.9) & $31(1.1)$ & 0.0044 & $0.62(0.45-0.87)$ \\
\hline \multicolumn{6}{|l|}{ Ethnicity/race } \\
\hline Black & $14,792(100)$ & $11,931(100)$ & $2,861(100)$ & $>0.99$ & \\
\hline $\begin{array}{l}\text { Body mass index } \\
\text { mean (SD) }\end{array}$ & $26.77(3.71)$ & $26.64(3.76)$ & $27.30(3.44)$ & $<0.0001$ & \\
\hline \multicolumn{6}{|l|}{ Parity } \\
\hline $\begin{array}{l}\text { Parity } \\
\text { mean (SD) }\end{array}$ & $1.72(1.96)$ & $1.76(1.99)$ & $1.55(1.75)$ & $<0.0001$ & \\
\hline $\mathrm{P}=0, n(\%)$ & $4,193(28.3)$ & $3,152(26.4)$ & $1,041(36.4)$ & $<0.0001$ & $1.45(1.35-1.55)$ \\
\hline $\mathrm{P}=1, n(\%)$ & $3,744(25.3)$ & $3,134(26.3)$ & $610(21.3)$ & $<0.0001$ & $0.80(0.74-0.87)$ \\
\hline $\mathrm{P}>1, n(\%)$ & $6,855(46.3)$ & $5,645(47.3)$ & $1,210(42.3)$ & $<0.0001$ & $0.85(0.79-0.91)$ \\
\hline \multicolumn{6}{|l|}{ Smoking status } \\
\hline Nonsmoker in pregnancy & $14,788(99.97)$ & $11,928(99.97)$ & $2,860(99.97)$ & & \\
\hline Smoked during pregnancy & $4(0.03)$ & $3(0.03)$ & $1(0.03)$ & 0.5768 & \\
\hline \multicolumn{6}{|l|}{ Domestic violence } \\
\hline Reported & $36(0.2)$ & $23(0.2)$ & $13(0.5)$ & & \\
\hline Not reported & $14,756(99.8)$ & $11,908(99.8)$ & $2,848(99.5)$ & 0.0193 & $1.87(1.21-2.89)$ \\
\hline \multicolumn{6}{|l|}{ Comorbidities } \\
\hline HIV Positive; $n$ (\%) & $933(6.3)$ & $625(5.2)$ & $308(10.8)$ & $<0.0001$ & $1.79(1.62-1.98)$ \\
\hline Syphilis; $n(\%)$ & $9(0.1)$ & $5(0.01)$ & $4(0.1)$ & 0.0771 & \\
\hline Malaria; $n(\%)$ & $96(0.6)$ & $64(0.5)$ & $32(1.1)$ & 0.0008 & $1.73(1.30-2.30)$ \\
\hline Tuberculosis; $n(\%)$ & $0(0.0)$ & $0(0.0)$ & $0(0.0)$ & $>0.99$ & \\
\hline Anemia; $n(\%)$ & $37(0.3)$ & $12(0.1)$ & $25(0.9)$ & $<0.0001$ & $3.52(2.80-4.41)$ \\
\hline Malnutrition; n (\%) & $10(0.1)$ & $5(0.04)$ & $5(0.2)$ & 0.0399 & $2.59(1.39-4.82)$ \\
\hline \multicolumn{6}{|l|}{ Pregnancy complications } \\
\hline Hypertensive disorders; $n(\%)$ & $306(2.04)$ & $49(0.43)$ & $257(9.0)$ & $<0.0001$ & $4.71(4.44-5.00)$ \\
\hline Gestational diabetes & $1(0.01)$ & $0(0.0)$ & $1(0.03)$ & 0.1934 & \\
\hline Preterm birth in prior pregnancy & $75(0.5)$ & $59(0.5)$ & $16(0.6)$ & 0.0849 & \\
\hline Cerclage placement & $3(0.02)$ & $3(0.03)$ & $0(0.0)$ & $>0.99$ & \\
\hline $\begin{array}{l}\text { Ultrasound performed } \\
\text { during pregnancy }\end{array}$ & $208(1.41)$ & $195(1.63)$ & $13(0.45)$ & $<0.0001$ & $1.17(1.12-1.20)$ \\
\hline
\end{tabular}

Abbreviation: SD, standard deviation.

${ }^{a}$ Chi-square test or Fisher's exact test performed for categorical variables, $t$-test for continuous variables and $t$-test with Welch's correction for unequal variances for maternal age and parity.

${ }^{\mathrm{b}}$ Relative risk and $95 \%$ confidence interval are shown, where appropriate.

(Chichewa) and social acceptance were not confounders in this study.

PTB in Malawi has been previously associated with malaria, anemia, and malnutrition. ${ }^{8}$ Additionally, the association of PTB with maternal age, ${ }^{24-26}$ nulliparity, ${ }^{27}$ domestic violence, ${ }^{28}$ HIV positive status, ${ }^{29}$ malaria, ${ }^{30}$ anemia, ${ }^{31-38}$ and malnutrition $^{39}$ has been previously reported in studies performed in other countries. HIV is particularly associated with PTB and other adverse perinatal outcomes among women who have not received antiretroviral therapy. ${ }^{29}$ 
Table 2 Reported maternal comorbidities by cluster and birth status

\begin{tabular}{|l|l|l|l|l|l|l|l|}
\hline & $\begin{array}{l}\text { Rural health } \\
\text { centers } \\
\text { (term) } \\
n(\%)\end{array}$ & $\begin{array}{l}\text { Rural health } \\
\text { centers } \\
\text { (preterm) } \\
n(\%)\end{array}$ & $\begin{array}{l}\text { Urban health } \\
\text { centers } \\
\text { (term) } \\
n(\%)\end{array}$ & $\begin{array}{l}\text { Urban health } \\
\text { centers } \\
\text { (preterm) } \\
n(\%)\end{array}$ & $\begin{array}{l}\text { Kamuzu } \\
\text { central } \\
\text { hospital } \\
\text { (term) } \\
n(\%)\end{array}$ & $\begin{array}{l}\text { Kamuzu } \\
\text { central } \\
\text { hospital } \\
\text { (preterm) } \\
n(\%)\end{array}$ & $p$-Value \\
\hline HIV positive & $232(2.82)$ & $24(3.83)$ & $351(11.07)$ & $42(17.65)$ & $33(7.75)$ & $239(12.08)$ & $<0.0001$ \\
\hline Syphilis positive & $1(0.01)$ & $1(0.16)$ & $4(0.13)$ & $0(0)$ & $0(0)$ & $3(0.15)$ & 0.0926 \\
\hline Prior preterm birth & $58(0.70)$ & $7(1.12)$ & $1(0.03)$ & $0(0)$ & $0(0)$ & $9(0.45)$ & $<0.0001$ \\
\hline Hypertension & $3(0.04)$ & $0(0)$ & $0(0)$ & $1(0.42)$ & $0(0)$ & $3(0.15)$ & 0.0181 \\
\hline $\begin{array}{l}\text { Preeclampsia/ } \\
\text { eclampsia }\end{array}$ & $4(0.05)$ & $2(0.32)$ & $2(0.06)$ & $5(2.10)$ & $12(2.82)$ & $246(12.43)$ & $<0.0001$ \\
\hline Prepregnancy diabetes & $2(0.02)$ & $0(0)$ & $1(0.03)$ & $0(0)$ & $0(0)$ & $3(0.15)$ & 0.2143 \\
\hline Gestational diabetes & $0(0)$ & $0(0)$ & $0(0)$ & $0(0)$ & $0(0)$ & $1(0.05)$ & 0.2678 \\
\hline $\begin{array}{l}\text { Cervical insufficiency } \\
\text { (cerclage) }\end{array}$ & $0(0)$ & $0(0)$ & $0(0)$ & $0(0)$ & $3(0.70)$ & $0(0)$ & $<0.0001$ \\
\hline $\begin{array}{l}\text { Malaria this } \\
\text { pregnancy }\end{array}$ & $48(0.58)$ & $21(3.35)$ & $16(0.50)$ & $5(2.10)$ & $0(0)$ & $6(0.30)$ & $<0.0001$ \\
\hline $\begin{array}{l}\text { Tuberculosis this } \\
\text { pregnancy }\end{array}$ & $0(0)$ & $0(0)$ & $0(0)$ & $0(0)$ & $0(0)$ & $0(0)$ & $\mathrm{NA}$ \\
\hline Anemia & $10(0.12)$ & $4(0.64)$ & $2(0.06)$ & $0(0)$ & $0(0)$ & $21(1.06)$ & $<0.0001$ \\
\hline $\begin{array}{l}\text { Smoking this } \\
\text { pregnancy }\end{array}$ & $0(0)$ & $0(0)$ & $2(0.06)$ & $0(0)$ & $1(0.23)$ & $1(0.05)$ & 0.0495 \\
\hline Domestic violence & $22(0.27)$ & $13(2.07)$ & $1(0.03)$ & $0(0)$ & $0(0)$ & $0(0)$ & $<0.0001$ \\
\hline Malnutrition & $3(0.04)$ & $0(0)$ & $2(0.06)$ & $0(0)$ & $0(0)$ & $5(0.25)$ & 0.0348 \\
\hline
\end{tabular}

Abbreviation: NA, not available.

Interventions aimed at reducing anemia and malnutrition, however, have not always resulted in reduced rates of PTB. $^{40-43}$ Nevertheless, other future interventions may prove beneficial. Finally, we found that women with PTB were less likely to have had an ultrasound. We were not able to discern whether this was due to a dating error or decreased antenatal care. In this population, clinically documented obstetric ultrasound occurs only among women who have attended antenatal clinics. However, not all clinics have ultrasound machines or capacity to scan all women (thus not all women are able to receive ultrasounds), so this is not a surrogate of having received antenatal care. Generally lower rates of ultrasound are seen among populations that lack adequate antenatal care, which has been associated with PTB elsewhere, but here, given that many clinics did not offer this service, it is more likely to be represented as a dating error. $^{44,45}$

The total number of home deliveries captured represented a small percentage of the overall births $(0.8 \%)$. This likely reflects underreporting. While we performed home visits with the intent of capturing deliveries that occurred at home, women may have been reticent to report home births. The Ministry of Health and, more locally, the heads of villages, have been discouraging women from purposely delivering at home, thus women may be reluctant to report home births to Community Health Workers due to fear of retaliation. Some communities also have to pay a fine which is imposed upon women who purposely deliver at home. ${ }^{46}$ This fine was created to disincentivize home births, but in this study, it may have led to underreporting of home births. This can also make it challenging to determine how many deliveries are not captured by local or health center delivery logs. Nationally, it is estimated that $88.9 \%$ of births occur within clinics or hospitals. ${ }^{47}$ While this varies by rural-urban location (88.1-94.9\%, respectively), our study included study sites in both rural and urban areas, and was located in the central region, which generally has the lowest rate of institutional delivery $(87.8 \%) .{ }^{47}$ Here, we focused on home visits to ensure that stillbirths and neonatal deaths were included. To capture more home deliveries in the future, efforts could focus on also capturing newborns presenting for immunizations or pediatric care.

The rate of identified gestational diabetes is low. This is likely related to demographics and screening practices. ${ }^{48}$ The population studied here is younger and less obese than many populations worldwide, which may also contribute to the low rate of gestational diabetes. ${ }^{49-52}$ The rate of hypertensive disorders among term deliveries was also low. The rate of prior PTB was substantially lower than expected. However, this data were derived from our interviews, and women may not have identified prior early neonatal deaths of small infants as potential preterm deliveries despite our request for them to do so; thus, this low rate may represent miscategorization.

Finally, the proportion of early PTBs ( $<32$ weeks of gestation) versus late PTBs (34-37 weeks of gestation) was nearly 
Estimated Preterm Birth Rate in Lilongwe Antony et al. e83

Table 3 Preterm birth rate estimates for actively surveyed urban and rural region surrounding Lilongwe, Malawi

\begin{tabular}{|c|c|c|c|c|c|c|c|}
\hline & \multirow{2}{*}{$\begin{array}{l}\text { Rural } \\
\text { health cen- } \\
\text { ters } \\
\text { Population } \\
177,463 \\
(n=8,861)\end{array}$} & \multirow{2}{*}{$\begin{array}{l}\text { Urban } \\
\text { health cen- } \\
\text { ters }\end{array}$} & \multicolumn{2}{|c|}{ Kamuzu central hospital } & \multirow{2}{*}{$\begin{array}{l}\begin{array}{l}\text { Home } \\
\text { birth/in } \\
\text { transit }\end{array} \\
(n=116)\end{array}$} & \multirow[t]{2}{*}{$p$-Value } & \multirow{2}{*}{$\begin{array}{l}\text { Mean } \\
\text { birth } \\
\text { weight } \\
(\mathrm{kg})\end{array}$} \\
\hline & & & $\begin{array}{l}\text { Total } \\
(n=2,405)\end{array}$ & $\begin{array}{l}\text { Referred from } \\
\text { rural or urban } \\
\text { health centers } \\
(n=1,865)\end{array}$ & & & \\
\hline $\begin{array}{l}\text { Total number of live } \\
\text { born births }\end{array}$ & $8,707(98.3)$ & $3,387(99.3)$ & $2,111(87.8)$ & $1,647(88.3)$ & $\begin{array}{l}112 \\
(96.6)\end{array}$ & $<0.0001$ & 3.073 \\
\hline Term births $\geq 37$ weeks & $8,234(92.9)$ & $3,172(93.0)$ & $426(17.7)$ & $399(21.4)$ & $99(85.3)$ & $<0.0001$ & 3.286 \\
\hline $\begin{array}{l}\text { Preterm births }<37 \\
\text { weeks (\%) }\end{array}$ & $627(7.1)$ & $238(7.0)$ & $1,979(82.3)$ & $1,456(78.1)$ & $17(14.7)$ & & 2.024 \\
\hline$\leq 32$ & $108(1.2)$ & $29(0.9)$ & $864(35.9)$ & $664(35.6)$ & $5(4.3)$ & & 1.684 \\
\hline$>32-33.86$ & $106(1.2)$ & $63(1.8)$ & $357(14.8)$ & $268(14.4)$ & $2(1.7)$ & & 2.124 \\
\hline$>34-<37$ & $192(2.2)$ & $98(2.9)$ & $347(14.4)$ & $261(14.0)$ & $4(3.4)$ & $<0.0001$ & 2.200 \\
\hline Preterm, GA unclear & $221(2.5)$ & $48(1.4)$ & $411(19.5)$ & $263(18.0)$ & $6(5.4)$ & & \\
\hline $\begin{array}{l}\text { Indicated preterm } \\
\text { births }^{\mathrm{a}}<37 \text { weeks (\%) }\end{array}$ & $0(0)$ & $1(0.03)$ & $183(7.61)$ & $179(9.60)$ & $0(0)$ & & 1.863 \\
\hline$\leq 32$ & $0(0)$ & $1(0.03)$ & $98(4.07)$ & $96(5.15)$ & $0(0)$ & & 1.652 \\
\hline$>32-33.86$ & $0(0)$ & $0(0)$ & $34(1.41)$ & $32(1.72)$ & $0(0)$ & & 2.181 \\
\hline$>34-<37$ & $0(0)$ & $0(0)$ & $51(2.21)$ & $51(2.73)$ & $0(0)$ & $<0.0001$ & 2.058 \\
\hline $\begin{array}{l}\text { Preterm caesarean de- } \\
\text { livery rate ( }<37 \text { weeks) }\end{array}$ & $5(0.06)$ & $1(0.03)$ & $642(26.7)$ & $475(25.5)$ & $0(0)$ & & 1.974 \\
\hline$\leq 32$ & $4(0.05)$ & $1(0.03)$ & $251(10.4)$ & $214(11.5)$ & $0(0)$ & & 1.715 \\
\hline$>32-34$ & $0(0)$ & $0(0)$ & $102(4.24)$ & $69(3.70)$ & $0(0)$ & & 2.152 \\
\hline$>34-<37$ & $0(0)$ & $0(0)$ & $135(5.61)$ & $105(5.63)$ & $0(0)$ & $<0.0001$ & 2.015 \\
\hline Macerated stillbirth & $15(0.17)$ & $6(0.18)$ & $134(5.57)$ & $96(5.15)$ & $3(2.59)$ & $<0.0001$ & 1.703 \\
\hline Early neonatal deaths & $21(0.24)$ & $5(0.15)$ & $126(5.24)$ & $90(4.83)$ & $0(0)$ & $<0.0001$ & 1.710 \\
\hline$\leq 1,500 \mathrm{~g}$ & $16(0.18)$ & $4(0.12)$ & $73(3.04)$ & $51(2.73)$ & $0(0)$ & & 2.088 \\
\hline$<1,500 \mathrm{~g}$ & $5(0.06)$ & $1(0.03)$ & $53(2.20)$ & $39(2.09)$ & $0(0)$ & $<0.0001$ & 1.113 \\
\hline
\end{tabular}

Abbreviation: GA, gestational age.

andicates live births.

equal. This is not consistent with what is seen in other populations worldwide. This finding is partly due to some late preterm deliveries being miscategorized as term deliveries.

The correlation between clinical dating and ultrasound dating, when available, was statistically significant, and the correlation was better for PTBs than term births. This suggests that we were unlikely to have miscategorized intrauterine growth restricted newborns as having been preterm.

Strengths of this study include the inclusion of women who lacked antenatal care who may be underrepresented in other studies, and the robust capture of data for deliveries occurred during this time period. Our findings were also generally consistent with prior studies.

\section{Limitations}

Limitations to this study include the low rate of obstetric ultrasound examinations to confirm dating criteria. While we noted the source of the "best obstetrical" estimated GA as recorded in the birth logs, very few had obstetric ultrasounds. Our ability to discern the etiology of early neonatal deaths was also limited, as these may have been due to prematurity alone or may have been due to undiagnosed congenital anomalies. The low rate of ultrasound examinations may also mean that cases were miscategorized as either term or preterm. Data on comorbidities were obtained only via interview for women who delivered at home, thus some diagnoses would be expected to have been missed. Similarly, for deliveries at the hospital, the method of diagnosing conditions varied from clinical assessment alone to laboratory verification and varied by site and woman. There are also limitations to determining whether transfers to $\mathrm{KCH}$ originated from the surrounding area. As the tertiary hospital, transfers may have originated from a center other than the four included here, thus may not truly represent the PTB rate in this region. We also have likely undersampled births that occurred outside the health centers. 

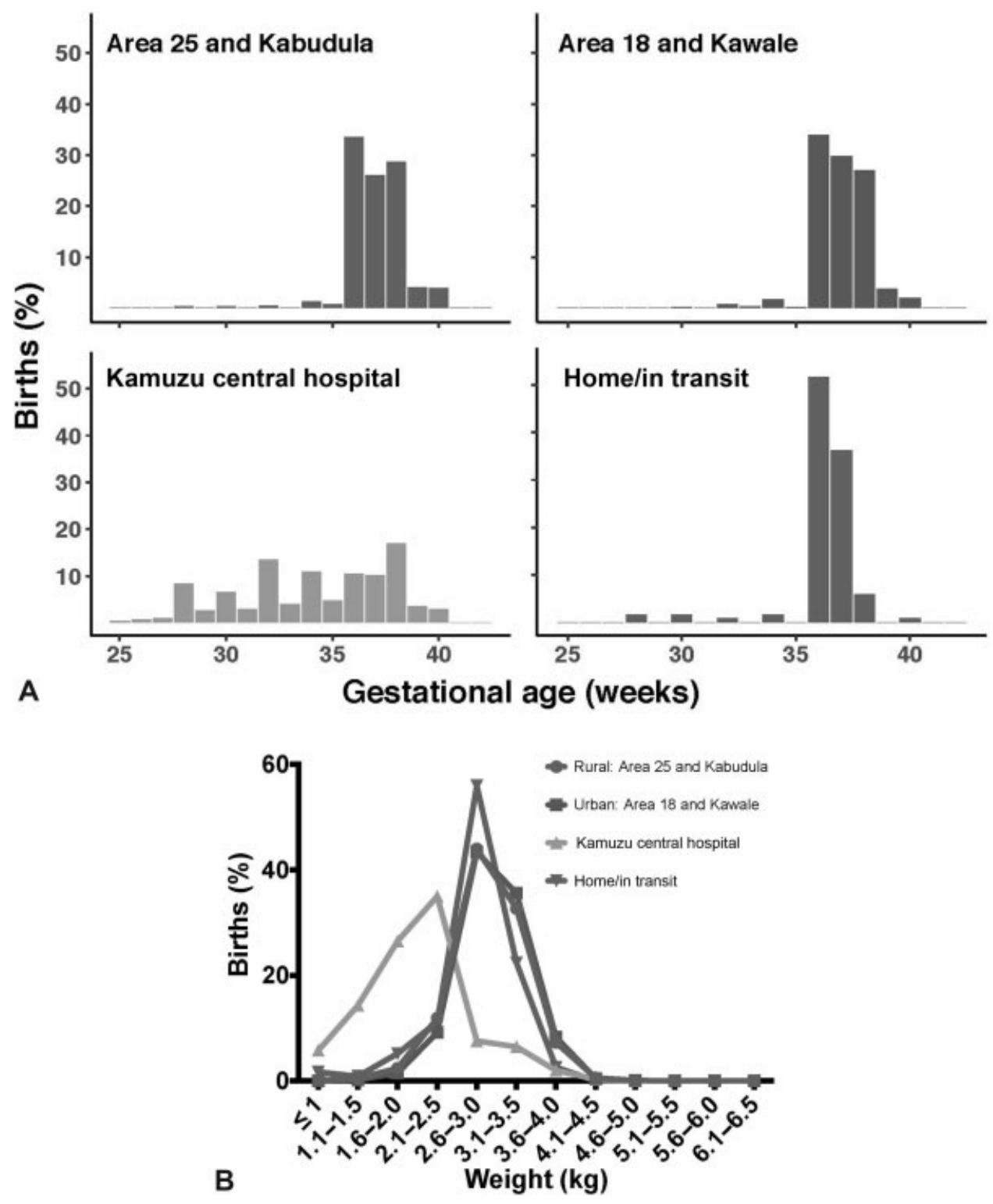

Fig. 1 (A) Percentage of births as a function of reported gestational age for each type of health center or referral hospital. (B) Percent of births as a function of birth weight for each type of health center or referral hospital.

\section{Conclusion}

In summary, we demonstrated that when performing a population-based estimation of the rate of PTB for areas within and surrounding Lilongwe, Malawi, including women without antenatal care and women delivering at home, the rate of PTB is $19.3 \%$ in this population. Therefore, given the high rate of PTB, Malawi, may be an ideal setting for future trials investigating the etiology of and treatments to prevent PTB.

Paper Presentation Information

Data from this paper were presented as a poster presentation at the Society of Maternal-Fetal Medicine's 34th Annual Meeting-The Pregnancy Meeting, New Orleans, Louisiana, February 3-8, 2014, Abstract Number 522 and the Society of Maternal-Fetal Medicine's 36th Annual Meeting-The Pregnancy Meeting, Atlanta, Georgia, February 1 to 6,2016 , Abstract Number 403 .
Financial Support

USAID/Bill \& Melinda Gates Foundation Saving Lives at Birth Grand Challenges Grant: AID-OAA-G-11-00062 (K. M.A.); E.W. Al Thrasher Foundation (K.M.A.); and NIH K12 GM084897 (R.M.P.). E.W. Al Thrasher Foundation, Foundation for the National Institutes of Health, (award no.: K12 GM084897) USAID/Bill \& Melinda Gates Foundation Saving Lives at Birth Grand Challenges Grant (grant no.: AID-OAA-G-11-00062).

Conflict of Interest/Disclosure Statement

The authors report no conflict of interest.

\section{Acknowledgments}

We would like to thank the Bill \& Melinda Gates Foundation, the E.W. Al Thrasher Foundation, and the NIH for their financial support. We would like to thank the patients for agreeing to participate in this study. We 
would like to also acknowledge Robert Koehler, medical librarian with UnityPoint Health-Meriter, for his assistance with reviewing the literature and procuring articles.

\section{References}

1 Liu L, Oza S, Hogan D, et al. Global, regional, and national causes of child mortality in 2000-13, with projections to inform post-2015 priorities: an updated systematic analysis. Lancet 2015;385 (9966):430-440

2 World Health Organization. Born too soon: the global action report on preterm birth. Available at: http://apps.who.int/iris/ bitstream/10665/44864/1/9789241503433_eng.pdf. Accessed February 13, 2020

3 Blencowe H, Cousens S, Oestergaard MZ, et al. National, regional, and worldwide estimates of preterm birth rates in the year 2010 with time trends since 1990 for selected countries: a systematic analysis and implications. Lancet 2012;379(9832):2162-2172

4 van den Broek N, Ntonya C, Kayira E, White S, Neilson JP. Preterm birth in rural Malawi: high incidence in ultrasound-dated population. Hum Reprod 2005;20(11):3235-3237

5 van den Broek NR, White SA, Goodall M, et al. The APPLe study: a randomized, community-based, placebo-controlled trial of azithromycin for the prevention of preterm birth, with meta-analysis. PLoS Med 2009;6(12):e1000191

6 Kulmala T, Vaahtera M, Ndekha M, et al. The importance of preterm births for peri- and neonatal mortality in rural Malawi. Paediatr Perinat Epidemiol 2000;14(03):219-226

7 Harjunmaa U, Järnstedt J, Alho L, et al. Association between maternal dental periapical infections and pregnancy outcomes: results from a cross-sectional study in Malawi. Trop Med Int Health 2015;20(11):1549-1558

8 van den Broek NR, Jean-Baptiste R, Neilson JP. Factors associated with preterm, early preterm and late preterm birth in Malawi. PLoS One 2014;9(03):e90128

9 van den Broek NR, White SA, Flowers C, et al. Randomised trial of vitamin A supplementation in pregnant women in rural Malawi found to be anaemic on screening by HemoCue. BJOG 2006;113 (05):569-576

10 Lawn JE, Gravett MG, Nunes TM, Rubens CE, Stanton C; GAPPS Review Group. Global report on preterm birth and stillbirth (1 of 7): definitions, description of the burden and opportunities to improve data. BMC Pregnancy Childbirth 2010;10(1, Suppl 1):S1

11 Goldenberg RL, Iams JD, Das A, et al; National Institute of Child Health and Human Development Maternal-Fetal Medicine Units Network. The preterm prediction study: sequential cervical length and fetal fibronectin testing for the prediction of spontaneous preterm birth. Am J Obstet Gynecol 2000;182(03):636-643

12 Gotsch F, Romero R, Kusanovic JP, et al. The anti-inflammatory limb of the immune response in preterm labor, intra-amniotic infection/inflammation, and spontaneous parturition at term: a role for interleukin-10.J Matern Fetal Neonatal Med 2008;21(08):529-547

13 Blank V, Hirsch E, Challis JR, Romero R, Lye SJ. Cytokine signaling, inflammation, innate immunity and preterm labour - a workshop report. Placenta 2008;29(Suppl A):S102-S104

14 Ma J, Prince A, Aagaard KM. Use of whole genome shotgun metagenomics: a practical guide for the microbiome-minded physician scientist. Semin Reprod Med 2014;32(01):5-13

15 Ganu RS, Ma J, Aagaard KM. The role of microbial communities in parturition: is there evidence of association with preterm birth and perinatal morbidity and mortality? Am J Perinatol 2013;30 (08):613-624

16 Gómez LM, Sammel MD, Appleby DH, et al. Evidence of a geneenvironment interaction that predisposes to spontaneous preterm birth: a role for asymptomatic bacterial vaginosis and DNA variants in genes that control the inflammatory response. Am J Obstet Gynecol 2010;202(04):386.e1-386.e6
17 Gotsch F, Gotsch F, Romero R, et al. The preterm parturition syndrome and its implications for understanding the biology, risk assessment, diagnosis, treatment and prevention of preterm birth. J Matern Fetal Neonatal Med 2009;22(May, Suppl 2):5-23

18 Lee J, Romero R, Xu Y, et al. A signature of maternal anti-fetal rejection in spontaneous preterm birth: chronic chorioamnionitis, anti-human leukocyte antigen antibodies, and C4d. PLoS One 2011;6(02):e16806

19 Romero R, Dey SK, Fisher SJ. Preterm labor: one syndrome, many causes. Science 2014;345(6198):760-765

20 Sorokin Y, Romero R, Mele L, et al. Maternal serum interleukin-6, C-reactive protein, and matrix metalloproteinase-9 concentrations as risk factors for preterm birth $<32$ weeks and adverse neonatal outcomes. Am J Perinatol 2010;27(08):631-640

21 Grobman WA, Lai Y, Landon MB, et al; Eunice Kennedy Shriver National Institute of Child Health and Human Development Maternal-Fetal Medicine Units Network. The change in the rate of vaginal birth after caesarean section. Paediatr Perinat Epidemiol 2011;25(01):37-43

22 Vaisbuch E, Romero R, Erez O, et al. Activation of the alternative pathway of complement is a feature of pre-term parturition but not of spontaneous labor at term. Am J Reprod Immunol 2010;63 (04):318-330

23 Committee on Practice Bulletins-Obstetrics and the American Institute of Ultrasound in Medicine. Practice bulletin no. 175: ultrasound in pregnancy. Obstet Gynecol 2016;128(06):e241e256

24 Azevedo WF, Diniz MB, Fonseca ES, Azevedo LM, Evangelista CB. Complications in adolescent pregnancy: systematic review of the literature. Einstein (Sao Paulo) 2015;13(04):618-626

25 Leftwich HK, Alves MVO. Adolescent pregnancy. Pediatr Clin North Am 2017;64(02):381-388

26 Kahveci B, Melekoglu R, Evruke IC, Cetin C. The effect of advanced maternal age on perinatal outcomes in nulliparous singleton pregnancies. BMC Pregnancy Childbirth 2018;18(01):343

27 Shah PS; Knowledge Synthesis Group on Determinants of LBW/PT births. Parity and low birth weight and preterm birth: a systematic review and meta-analyses. Acta Obstet Gynecol Scand 2010; 89(07):862-875

28 Donovan BM, Spracklen CN, Schweizer ML, Ryckman KK, Saftlas AF. Intimate partner violence during pregnancy and the risk for adverse infant outcomes: a systematic review and meta-analysis. BJOG 2016;123(08):1289-1299

29 Wedi COO, Kirtley S, Hopewell S, Corrigan R, Kennedy SH, Hemelaar J. Perinatal outcomes associated with maternal HIV infection: a systematic review and meta-analysis. Lancet HIV 2016;3(01):e33-e48

30 Lagerberg RE. Malaria in pregnancy: a literature review. J Midwifery Womens Health 2008;53(03):209-215

31 Klebanoff MA, Shiono PH, Selby JV, Trachtenberg AI, Graubard BI. Anemia and spontaneous preterm birth. Am J Obstet Gynecol 1991;164(1, Pt 1):59-63

32 Allen LH. Anemia and iron deficiency: effects on pregnancy outcome. Am J Clin Nutr 2000;71(5, Suppl):1280S-1284S

33 Yi S-W, Han Y-J, Ohrr H. Anemia before pregnancy and risk of preterm birth, low birth weight and small-for-gestational-age birth in Korean women. Eur J Clin Nutr 2013;67(04):337-342

34 Lu ZM, Goldenberg RL, Cliver SP, Cutter G, Blankson M. The relationship between maternal hematocrit and pregnancy outcome. Obstet Gynecol 1991;77(02):190-194

35 Scholl TO, Hediger ML, Fischer RL, Shearer JW. Anemia vs iron deficiency: increased risk of preterm delivery in a prospective study. Am J Clin Nutr 1992;55(05):985-988

36 Singh K, Fong YF, Arulkumaran S. Anaemia in pregnancy-a crosssectional study in Singapore. Eur J Clin Nutr 1998;52(01): 65-70

37 Rahman MM, Abe SK, Rahman MS, et al. Maternal anemia and risk of adverse birth and health outcomes in low- and middle-income 
countries: systematic review and meta-analysis. Am J Clin Nutr 2016;103(02):495-504

38 Oaks BM, Jorgensen JM, Baldiviez LM, et al. Prenatal iron deficiency and replete iron status are associated with adverse birth outcomes, but associations differ in Ghana and Malawi. J Nutr 2019;149(03):513-521

39 Bloomfield FH. How is maternal nutrition related to preterm birth? Annu Rev Nutr 2011;31(01):235-261

40 Shah R, Mullany LC, Darmstadt GL, et al; ProjAHNMo Study Group in Bangladesh. Incidence and risk factors of preterm birth in a rural Bangladeshi cohort. BMC Pediatr 2014;14(01):112

41 Papadopoulou E, Stratakis N, Roumeliotaki T, et al. The effect of high doses of folic acid and iron supplementation in early-to-mid pregnancy on prematurity and fetal growth retardation: the mother-child cohort study in Crete, Greece (Rhea study). Eur J Nutr 2013;52(01):327-336

42 Brannon PM, Taylor CL. Iron supplementation during pregnancy and infancy: uncertainties and implications for research and policy. Nutrients 2017;9(12):1-17

43 Sengpiel V, Bacelis J, Myhre R, et al. Folic acid supplementation, dietary folate intake during pregnancy and risk for spontaneous preterm delivery: a prospective observational cohort study. BMC Pregnancy Childbirth 2014;14(01):375

44 Cox RG, Zhang L, Zotti ME, Graham J. Prenatal care utilization in Mississippi: racial disparities and implications for unfavorable birth outcomes. Matern Child Health J 2011;15(07):931-942

45 Wehby GL, Pawluk M, Nyarko KA, López-Camelo JS. Explaining ethnic disparities in preterm birth in Argentina and Ecuador. Glob Public Health 2018;13(08):1126-1143
46 Antony KM, Levison J, Suter MA, et al. Qualitative assessment of knowledge transfer regarding preterm birth in Malawi following the implementation of targeted health messages over 3 years. Int J Womens Health 2019;11:75-95

47 UNICEF. Maternal and Newborn Health Disparities: Malawi. Available at: https://webcache.googleusercontent.com/search? q=cache:Gh4GSOK-FdcJ:https://data.unicef.org/wp-content/uploads/country_profiles/Malawi/country\% 2520profile_MWI.pdf $+\& c d=3 \& \mathrm{hl}=\mathrm{en} \& \mathrm{ct}=\mathrm{clnk} \& \mathrm{gl}=\mathrm{in}$. Accessed February 13, 2020

48 Macaulay S, Dunger DB, Norris SA. Gestational diabetes mellitus in Africa: a systematic review. PLoS One 2014;9(06):e97871

49 Vogel JP, Souza JP, Mori R, et al; WHO Multicountry Survey on Maternal and Newborn Health Research Network. Maternal complications and perinatal mortality: findings of the World Health Organization Multicountry Survey on Maternal and Newborn Health. BJOG 2014;121(Suppl 1):76-88

50 Kim SY, Sharma AJ, Sappenfield W, Wilson HG, Salihu HM. Association of maternal body mass index, excessive weight gain, and gestational diabetes mellitus with large-for-gestational-age births. Obstet Gynecol 2014;123(04):737-744

51 Di Cesare M, Bentham J, Stevens GA, et al; NCD Risk Factor Collaboration (NCD-RisC). Trends in adult body-mass index in 200 countries from 1975 to 2014: a pooled analysis of 1698 population-based measurement studies with 19.2 million participants. Lancet 2016;387(10026):1377-1396

52 Xiao L, Ding G, Vinturache A, et al. Associations of maternal prepregnancy body mass index and gestational weight gain with birth outcomes in Shanghai, China. Sci Rep 2016;7:41073 